\title{
Administradores diante dos riscos ocupacionais que envolvem as atividades da equipe de enfermagem no ambiente hospitalar
}

\author{
Administrators in face of occupational risks that involve the activities of the nursing team in the \\ hospital environment
}

José Angelo Leal Braga"

Sociedade Brasileira de Terapia Intensiva (Sobrati), Faculdades Unificadas Serra dos Órgãos (Unifeso), Teresópolis, Rio de Janeiro, Brasil. *Autor para correspondência. E-mail: joseangelo.braga@hotmail.com

Resumo: Os riscos ocupacionais a que se sujeitam uma equipe de enfermagem têm sido alvo de muitas discussões, tornando-se um tema de suma importância, reflexo da relevância da segurança ocupacional como fator preponderante e garantidor da boa prática profissional e do respeito à vida. Diversas pesquisas apontam os riscos químicos, biológicos, ergonômicos, físicos e os riscos mentais como os principais riscos ocupacionais. Este artigo, discutindo e disponibilizando uma breve revisão de literatura sobre os riscos ocupacionais em saúde, tem como objetivo torna-se um instrumento informacional, contribuindo para a atenuação da exposição de profissionais de enfermagem aos inevitáveis riscos a que a sua própria prática está sujeita. O corpo humano comporta várias funções, estas que feita de forma inadequada pode levar a sérios riscos, como a doença ocupacional. Se preocupar com a Saúde Ocupacional dos funcionários, é um dever do gestor e que ajuda a garantir o bem-estar, contribuindo para a sua produtividade, motivação, atuação, redução de danos, melhores resultados e satisfação no trabalho. Contudo, acredita-se que as empresas devem verificar pontos importantes e adotar estratégias que ajudem a tornar o ambiente de trabalho cada vez mais agradável e menos insalubre possível. A análise possibilitará que a empresa tenha ciência da real situação da qual estabelece aos seus funcionários, levando a encontrar estratégias que ajudem a melhorar as condições físicas e mentais dos seus trabalhadores, agregando satisfação e motivação em seus dias contínuos de trabalho. No entanto, torna-se importante utilizar instrumentos de medida de gravidade, avaliar as necessidades dos cuidados e a demanda de trabalho de enfermagem, buscando qualificar os profissionais que dediquem maior tempo na atenção às necessidades de apoio emocional e informação aos pacientes e familiares, otimização de recursos, redução de custos e, consequentemente, qualidade e humanização da assistência.

Palavras-chave: administração hospitalar, enfermeiro gestor, riscos ocupacionais, ambiente hospitalar.

Abstract: The occupational risks that are subjected to a nursing team have been the subject of many discussions", become a topic of paramount importance, reflecting the relevance of occupational safety as a preponderant factor and guaranteed by good professional practice and respect for life. Several researches aimed at chemical, biological, ergonomic, physical and mental risks as the main occupational risks. This article, discussed and made available a brief review of the literature on occupational health risks, aims to become an informative tool, contributing to mitigate the exposure of nursing professionals to unavoidable risks and that their own practice is subject to. The human body has several functions; those that are improperly formed can lead to serious risks, such as an occupational disease. Concerning employees' Occupational Health is a manager's duty and helps to ensure well-being, contributing to their investigation, motivation, performance, harm reduction, better results and job satisfaction. However, he believes that companies should check important points and adopt strategies that help to make the work environment more pleasant and less unhealthy as possible. The analysis allows the company to be aware of the real situation of the requirements defined for its employees, leading to finding information that helps to improve the working and mental conditions of its workers, adding satisfaction and motivation in their continuous work days. However, it is important to use severity measurement instruments, assess the needs for care with the demand for nursing work, seek to qualify professionals who dedicate more time to the needs of emotional support and information to patients and families, optimization of resources, cost reduction and, consequently, quality and humanization of assistance.

Keywords: hospital administration, nurse manager, occupational risks, hospital environment. 


\section{Introdução}

Atualmente a organização hospitalar é uma das mais complexas, não apenas pela nobreza e amplitude da sua missão, mas, sobretudo, por apresentar uma equipe multidisciplinar com elevado grau de autonomia, para dar assistência à saúde em caráter preventivo, curativo e realibilitador a pacientes em regime de internação, onde se utiliza tecnologia de ponta de rotina e crescentemente. E se constitui, ainda, num espaço de prática de ensino-aprendizagem e produção científica (Azevedo, 1993).

As transformações ocorridas nas últimas décadas no mundo do trabalho têm repercutido na saúde dos indivíduos e do coletivo de trabalhadores de forma intensiva. A incorporação crescente da microeletrônica, da informática, da telemática e da robótica somada a um novo e complexo conjunto de inovações organizacionais modificou profundamente a estrutura produtiva dos países capitalistas avançados e, em níveis diferenciados, a dos países de desenvolvimento capitalista tardio, como é o caso do Brasil, provocando mudanças profundas na organização, nas condições e nas relações de trabalho.

O hospital, no transcurso de sua história, experimenta distintos processos de reorganização. De abrigo para pobres e viajantes transforma-se em centro de alta tecnologia para diagnostico, tratamento e pesquisas. Isto lhe confere uma complexidade ímpar, pois mescla a nobre missão social de cuidar das pessoas com traços administrativos e econômicos comuns a outras organizações de negócios. O administrador hospitalar, que chega aos hospitais para fazer frente a esta complexidade, acaba centrando suas atividades na busca do bom funcionamento e da sobrevivência organizacionais.

O hospital, de maneira geral, é reconhecido como um ambiente insalubre, penoso e perigoso para os que ali trabalham. No ambiente hospitalar há multiplicidade de riscos aos trabalhadores, sendo que, basicamente, parecem existir os: biológicos, físicos, químicos, psicossociais e ergonômicos. Os primeiros são os responsáveis por infecções agudas e crônicas, ocasionadas por vírus, fungos e bactérias. Os físicos são aqueles causados pelas radiações, vibrações, ruídos, temperatura ambiental, iluminação e eletricidade.

Este estudo teve como objetivo descrever sobre a atuação do administrador diante dos principais riscos ocupacionais que os trabalhadores estão expostos no ambiente hospitalar.

\section{Metodologia}

Esta pesquisa é do tipo bibliográfica e segundo Lakatos e Marconi (2002) um trabalho bibliográfico não é mera repetição do que já foi dito ou escrito sobre certo assunto, mais ajuda ao exame de um tema, visto de uma outra forma ou abordagem, chegando a resultados inovadoras.

Para Severino (1996), antes de começarmos a desenvolver um trabalho, devemos elaborar o plano de ação. Diante do material levantado, partimos para a leitura e análise, após realiza-se o fichamento para elaboração da introdução do trabalho e seu desenvolvimento.

A pesquisa bibliográfica não deve ser confundida com a pesquisa documental. $O$ estudo descritivo possibilita o desenvolvimento de um nível de analise em que nos permite identificar as diferentes formas dos fenômenos, sua ordenação e classificação. Oliveira (2001)

Conforme Ruiz (1996), o pesquisador deverá buscar em fontes bibliográficas as passagens que possam contribuir para o esclarecimento do tema em elaboração. A leitura, portanto, inicia-se com o objetivo de coletar material para resolver determinado problema, deverá ser criteriosa e seletiva.

\section{Revisão de literatura}

\section{Saúde do trabalhador}

O hospital é o principal local de trabalho dos membros da equipe de saúde e outros que, frequentemente, permanecem a maior parte de sua vida produtiva dentro desse ambiente, muitas vezes em mais de um turno de trabalho, devido aos baixos salários (Bulhões, 1994; Takeda, 1996). Essa instituição, na qual se tenta salvar vidas e recuperar a saúde perdida das pessoas enfermas é a mesma que favorece o adoecer das pessoas que nela trabalham, porque, aparentemente, não há preocupação com a proteção, promoção e manutenção da saúde de seus empregados (Takeda, 1996).

Miranda e Stancato (2008) mostra em seu artigo que no Brasil, a preocupação com a questão da saúde dos trabalhadores hospitalares iniciou-se na década de 1970, quando pesquisadores da Universidade de São Paulo (USP) enfocaram a saúde ocupacional em trabalhadores hospitalares. Esse estudo citou a ocorrência de 4.468 acidentes de trabalho em hospitais do país. Queixas como doenças infectocontagiosas, lombalgias, reações 
alérgicas, fadigas e acidentes do trabalho foram referidos por 26 grupos ocupacionais de trabalhadores hospitalares em 1976, ao passo que, em 1988, estudo realizado no Hospital das Clínicas da Universidade de São Paulo, envolvendo 1.506 acidentes levantou que as principais causas de afastamento foram lacerações e ferimentos, contusões ou torções.

Segundo a Organização Mundial de Saúde - OMS (1994) há um favorecimento da saúde física e mental quando o trabalho se adapta as condições do trabalhador e quando os riscos para a saúde estão sob controle. Os trabalhadores, vive-se uma realidade de trabalho cansativo e desgastante para os trabalhadores, em que as pessoas convivem com a dor e o sofrimento.

As doenças ocupacionais e os acidentes de trabalho constituem-se em importantes questões de saúde pública que ainda precisam ser mais bem discutidas, porque os acidentes de trabalho são os agravos mais documentados em relação à saúde do trabalhador, mesmo sabendo-se ainda que existam profissionais de saúde que não os notificam. (Kirchhof \& Capellari, 2004).

\section{Sobrecarga e jornadas fatigantes nos profissionais no ambiente hospitalar}

Os trabalhadores hospitalares vêm atualmente argumentando de forma mais fundamentada, a inadequação numérica e qualitativa dos recursos, comprometendo a qualidade da assistência prestada devido à sobrecarga de trabalho.

Sabe-se que todos os métodos empregados para analises irão detectar um aumento na carga de trabalho da enfermagem, criando um ciclo vicioso com maior incidência de infecção hospitalar, repercutindo em estadias, custos e trabalho. Os gerentes hospitalares devem estar atentos a este problema e idealmente adequar o seu quadro, levando-se em consideração que a sobrecarga da enfermagem favorece falhas na realização nas medidas básicas de controle das infecções, aumentando sua ocorrência e consequentemente o seu trabalho, sendo necessário corrigir estas deficiências de pessoal.

É visto que, hoje em dia, que a fadiga é um dos fatores responsáveis por alterações do estado de saúde e de bemestar do indivíduo que podem levar à doença e à morte. Por outro lado, têm-se multiplicado os esforços de pesquisa de especialistas e de instituições no sentido de propor mecanismos que visem controlar os aspectos negativos no trabalho. Essa necessidade de ação passou a ser particularmente visível no campo do controle do estresse, por ter sido provada a possibilidade de se prevenir a morbidade e impedir a mortalidade ocasionada por ele, (Lima, 2000).

A palavra stress primeiramente utilizada na física, indicando o desgaste sofrido por materiais expostos a pressões ou forças. A palavra stress, derivada do latim, foi utilizada pela primeira vez no sentido psicológico no século XVIII. Porém, foi inicialmente usada na área da saúde por Hans Selye, na época estudante de medicina, em 1926, ao perceber que muitas pessoas sofriam de várias doenças físicas e apresentavam algumas queixas em comum como, fadiga, hipertensão, desânimo e falta de apetite. Em 1936, já então endocrinologista, introduziu o termo stress para designar uma síndrome produzida por vários agentes nocivos. Enfatiza a resposta não específica do organismo a situações que não o debilitam, enfraquecendo e levando o organismo a adoecer (Spilberger, 1979).

Para Marziale (1995), os trabalhadores hospitalares estão constantemente expostos aos riscos ocupacionais, relacionados aos agentes físicos, químicos e biológicos e a fatores ergonômicos e psicossociais.

$\mathrm{O}$ trabalho desenvolvido em hospitais requer que todos os profissionais tenham suficiente experiência clínica e maturidade que permita enfrentar e tomar decisões difíceis, geralmente com implicações éticas e morais (Albaladejo et al., 2004).

O trabalhador que atua em instituições hospitalares está exposto a diferentes estressores ocupacionais que afetam diretamente o seu bem-estar. Dentre vários, podemos citar as longas jornadas de trabalho, o número insuficiente de pessoal, a falta de reconhecimento profissional, a alta exposição do profissional a riscos químicos e físicos, assim como o contato constante com o sofrimento, a dor e muitas vezes a morte. $\mathrm{O}$ desempenho destes profissionais envolve uma série de atividades que necessitam forçadamente de um controle mental e emocional muito maior que em outras profissões

Benevides \& Pereira (2002) mostra a necessidade que os profissionais têm que manejar com pacientes em estado grave; devem compartilhar com o enfermo e seus familiares a angústia, a dor, a depressão; e o medo de padecerem.

No Brasil de maneira geral a relação saúde-trabalho é muito problemática, devido especialmente a inexistência de condições de vida e trabalho satisfatórias. Essa precariedade pode ser detectada, dentre as várias determinações da referida relação, através da elevada incidência de acidentes de trabalho e doenças ocupacionais, mesmo que as notificações encontradas não coincidam coma realidade. Direcionando atenção a atenção aos trabalhadores, constata-se através da literatura (Lopes, 1988; Marziale, Melo, 1986; Aquino et al., 1993), que seus profissionais possuem condições de trabalho insatisfatórias devido a inúmeros fatores que vão desde a baixa remuneração à esquemas de horários de trabalho adotados. 
A atividade de administração é caracterizada pela promoção, manutenção e restabelecimento das necessidades básicas do indivíduo, em especial quando este é atingido em sua integridade física e/ou mental.

Atualmente no Brasil, essas atividades são realizadas por profissionais que se encontram subdivididos segundo preparo. São eles: enfermeiros, técnicos e auxiliares de Enfermagem e atendentes sendo que, essa última categoria não é regulamentada por lei (COFEN, 1985).

No que diz respeito às enfermeiras, Pottler e Estryn-Behar (1979), assinalam que essa categoria profissional se depara com uma série de dificuldades ocasionadas pela carga física e mental sofrida na prestação da assistência, pela alteração dos ritmos biológicos devido a constantes mudanças de turnos e ainda devido às condições de alimentação e transporte.

Especificamente em relação à carga mental, tem-se que a diversidade e a complexidade dos procedimentos técnicos, a hierarquização, a organização do trabalho e a confrontação cotidiana com o sofrimento, dor e morte são causadores de carga mental excessiva no trabalho das enfermeiras, os quais podem levar a fadiga.

Fadiga é um fenômeno preocupante da situação de trabalho de difícil conceituação, interpretação e aferição e que se torna complexo, porque serve para nomear um estado global resultante do desequilíbrio interno devido ao sistema de relações do organismo.

Entende-se após longa revisão da literatura, que a fadiga, pode atingir indivíduos de todas as faixas etárias, no desenvolvimento de qualquer tipo de atividade realizada por um período de tempo, que além de ser um fenômeno que causa mal-estar, provoca alterações no estado psicossomático, podendo ser encarado como resultante de esforço físico e/ou mental associado às condições do ambiente, fatores psicológicos inerentes ao regime de trabalho, condições individuais e as condições de trabalho.

Segundo Wisner (1987) toda situação de trabalho tem pelo menos três aspectos; físico cognitivo e psíquico e cada um deles pode determinar uma sobrecarga.

O trabalho se toma perigoso ao aparelho psíquico tão logo ele se oponha a sua livre atividade. Cada indivíduo possui suas formas de descargas preferenciais; a satisfação e o prazer no trabalho são potentes formas de descargas psíquicas.

Se um trabalhador permite a diminuição da carga psíquica, ele está em equilíbrio; no inverso ocorre sobrecarga devido ao acúmulo de energia levando a um estado de tensão e desprazer, consequentemente propiciando o aparecimento da fadiga mental.

A fadiga mental pode ser originada pelo inter-relacionamento de fatores profissionais e/ou extraprofissionais e as características do indivíduo. Entre os fatores pode-se ressaltar: iluminação inadequada, desconforto térmico, sonoro, pausas insuficientes, jornadas prolongadas esquemas de turnos, vícios posturais, trabalho monótono e repetitivo, mau relacionamento, responsabilidade, salário, alta concentração mental e ambiente de trabalho estressante, baixo padrão de vida, problemas de alimentação, habitação, vestuário, transporte, assistência social e médica (Esposito et al., 1980).

\section{Desgaste físico e emocional}

O trabalhador que atua em instituições hospitalares está exposto a diferentes estressores ocupacionais que afetam diretamente o seu bem-estar. Dentre vários, podemos citar as longas jornadas de trabalho, o número insuficiente de pessoal, a falta de reconhecimento profissional, a alta exposição do profissional a riscos químicos e físicos, assim como o contato constante com o sofrimento, a dor e muitas vezes a morte. $\mathrm{O}$ desempenho destes profissionais envolve uma série de atividades que necessitam forçadamente de um controle mental e emocional muito maior que em outras profissões (Benevides-Pereira, 2002).

Assim, estressores ocupacionais, quando persistentes, podem levar à Síndrome de Burnout (SB). Síndrome considerada por França e Rodrigues (1999) como uma resposta emocional a situações de estresse crônico em função de relações intensas em situações de trabalho com outras pessoas. Segundo Carlotto e Gobbi (1999), a definição de Burnout mais utilizada e aceita na comunidade científica é a fundamentada na perspectiva social psicológica.

Nesta, a Síndrome de Burnout (SB) é entendida como um processo constituído por três dimensões: Exaustão Emocional (EE), Despersonalização (DE) e Baixa Realização Profissional (BRP) (Maslach \& Jackson, 1985). A Exaustão Emocional é caracterizada pela falta ou carência de energia, entusiasmo e por sentimento de esgotamento de recursos. Os trabalhadores acreditam que já não têm condições de despender mais energia para o atendimento de seu cliente ou demais pessoas como faziam antes. A Despersonalização faz com que o profissional passe a tratar os clientes, colegas e a organização como objetos, de maneira que pode desenvolver insensibilidade emocional. Já a Baixa Realização Profissional revela-se por uma tendência do trabalhador em se auto avaliar de forma negativa. As pessoas sentem-se infelizes com elas próprias e insatisfeitas com seu desenvolvimento profissional. 
Vários estudos têm demonstrado que o Burnout incide principalmente sobre os profissionais de ajuda, que prestam assistência ou são responsáveis pelo desenvolvimento ou cuidado de outros (Benevides-Pereira, 2002). De acordo com Lautert (1997), existem algumas explicações para a ocorrência desse fenômeno. Uma delas seriam o rápido desenvolvimento tecnológico, a divisão e expansão das especialidades médicas, que determinam o hospital como um complexo sistema de divisão do trabalho, com elevada hierarquia de autoridade, com canais formais de comunicação e um grande conjunto de regras e normas para seu funcionamento. Assim, existem neste contexto duas linhas paralelas de autoridade: a administrativa e a profissional, sendo frequente o surgimento de conflitos devido a diferentes conjuntos de valores. Este confronto, que se repete continuamente, é gerador de ansiedade e estresse, que pode contribuir para a baixa motivação profissional em profissionais da saúde.

O conhecimento dos aspectos teóricos e práticos dos profissionais de enfermagem tem nos levado a refletir sobre possíveis situações enfrentadas pelas equipes frente a essa nova forma de assistência.

Observamos que algumas situações na relação trabalhador-usuário demandam um certo gasto de energia e adaptação, como o contato direto com a realidade e/ou sofrimento do próximo, elementos próprios do tipo de trabalho, como uma certa identificação e os laços afetivos acompanham a exposição prolongada do estressor”. Tal síndrome apresenta três fases ou estágios

$1^{\text {a }}$ - fase de alarme: O organismo tem uma excitação de agressão ou de fuga ao estressor, que pode ser entendida como um comportamento de adaptação. Nos dois casos, reconhece-se uma situação de reação saudável ao estresse, porquanto possibilita o retorno à situação de equilíbrio após a experiência estressante. Essa fase é caracterizada por alguns sintomas: taquicardia, tensão crônica, dor de cabeça, sensação de esgotamento, hipocloremia, pressão no peito, extremidades frias, dentre outros.

$2^{a}$ - fase de resistência: Havendo persistência da fase de alerta, o organismo altera seus parâmetros de normalidade e concentra a reação interna em um determinado órgão-alvo, desencadeando a Síndrome de Adaptação Local (SAL). Nessa fase, ocorre a manifestação de sintomas da esfera psicossocial, como ansiedade, medo, isolamento social, roer unhas, oscilação do apetite, impotência sexual e outros.

$3^{\text {a }}$ - fase de exaustão: $O$ organismo encontrasse extenuado pelo excesso de atividades e pelo alto consumo de energia. Ocorre, então, a falência do órgão mobilizado na SAL, o que se manifesta sob a forma de doenças orgânicas, (Lipp, 1996).

Riscos Biológicos, infecciosos, químicos e ergonômicos

\begin{tabular}{|c|c|c|c|}
\hline GRUPO & RISCOS & $\begin{array}{c}\text { COR } \\
\text { DE } \\
\text { IDENTIFICAÇAO }\end{array}$ & EXEMPLOS \\
\hline 01 & Fisicos & Verde & $\begin{array}{c}\text { Ruído, calor, frio, pressäes, } \\
\text { umidade, radiaçöes ionizantes } \\
\text { e näo ionizantes, vibraçöes etc. }\end{array}$ \\
\hline 02 & Quimicos & Vermelho & $\begin{array}{c}\text { Poeiras, fumos, gases, } \\
\text { vapores, névoas, neblinas etc. }\end{array}$ \\
\hline 04 & Biológicos & Marron & $\begin{array}{c}\text { Fungos, vírus, parasitas. } \\
\text { bactérias, protozoários, } \\
\text { insetos etc. }\end{array}$ \\
\hline 05 & Acidentes & Amarela & $\begin{array}{c}\text { Levantamento e transporte } \\
\text { manual de peso, monotonia, } \\
\text { repetividade, responsabilidade, } \\
\text { ritmo excessivo, posturas } \\
\text { inadequadas de trabalho. } \\
\text { trabalho em turnos etc. }\end{array}$ \\
\hline Azul & $\begin{array}{c}\text { Arranjo físico inadequado, } \\
\text { iluminaçäo inadequada, } \\
\text { incêndio e explosão, } \\
\text { eletricidade, maquinas e } \\
\text { equipamentos sem proteçäo, } \\
\text { queda e animais peçonhentos. }\end{array}$ \\
\hline
\end{tabular}

Fonte: Newmed, 2007.

Para cada tipo de risco os círculos serão representados por uma cor diferente, conforme segue:

Riscos físicos: verde;

Riscos químicos: vermelho;

Riscos biológicos: marrom;

Riscos ergonômicos: amarelo;

Riscos de acidentes/mecânicos: azul. 


\section{Riscos biológicos}

O ambiente de trabalho hospitalar tem sido considerado insalubre por agrupar pacientes portadores de diversas enfermidades infectocontagiosas e viabilizar muitos procedimentos que oferecem riscos de acidentes e doenças para os trabalhadores da saúde. Os trabalhadores potencialmente expostos aos riscos precisam estar informados e treinados para evitar problemas de saúde, e métodos de controle devem ser instituídos para prevenir acidentes. Esses métodos podem ser usados para riscos ambientais, incluindo a substituição do agente de risco, controles de engenharia, práticas de trabalho, equipamentos de proteção pessoal, controles administrativos e programas de exames médicos (NIOSH, 1988).

Consideram-se riscos ambientais os agentes físicos, químicos e biológicos existentes no ambiente de trabalho, que, dependendo da sua natureza, concentração ou intensidade e tempos de exposição são capazes de causar danos à saúde dos trabalhadores (Ministério do Trabalho, 2001) e riscos ocupacionais todas as situações de trabalho que podem romper o equilíbrio físico, mental e social das pessoas, e não somente as situações que originem acidentes e enfermidades (Funden, 1996).

Os riscos biológicos, no âmbito das Normas Regulamentadoras de Segurança e Saúde no Trabalho - NR, incluemse no conjunto dos riscos ambientais, junto aos riscos físicos e químicos, conforme pode ser observado pela transcrição do item 9.1.5 da Norma Regulamentadora nº 9 - Programa de Prevenção de Riscos Ambientais - PPRA:

Para efeito desta NR, consideram-se riscos ambientais os agentes físicos, químicos e biológicos existentes nos ambientes de trabalho que, em função de sua natureza, concentração ou intensidade e tempo de exposição, são capazes de causar danos à saúde do trabalhador.

O reconhecimento dos riscos ambientais é uma etapa fundamental do processo que servirá de base para decisões quanto às ações de prevenção, eliminação ou controle desses riscos. Reconhecer o risco significa identificar, no ambiente de trabalho, fatores ou situações com potencial de dano à saúde do trabalhador ou, em outras palavras, se existe a possibilidade deste dano.

Para se obter o conhecimento dos riscos potenciais que ocorrem nas diferentes situações de trabalho é necessária a observação criteriosa e in loco das condições de exposição dos trabalhadores.

$\mathrm{Na}$ área de saúde, alguns exemplos poderiam ser: atividades de pesquisa ou desenvolvimento que envolva a manipulação direta de agentes biológicos, atividades realizadas em laboratórios de diagnóstico microbiológico, atividades relacionadas à biotecnologia (desenvolvimento de antibióticos, enzimas e vacinas, entre outros).

NR 32 - Manual de Legislação Atlas (2007), Segurança e Saúde no Trabalho em Serviços de Saúde e os Riscos Biológicos:

\section{Objetivo e campo de aplicação}

Esta Norma Regulamentadora - NR tem por finalidade estabelecer as diretrizes básicas para a implementação de medidas de proteção à segurança e à saúde dos trabalhadores dos serviços de saúde, bem como daqueles que exercem atividades de promoção e assistência à saúde em geral.

Para fins de aplicação desta NR entende-se por serviços de saúde qualquer edificação destinada à prestação de assistência à saúde da população, e todas as ações de promoção, recuperação, assistência, pesquisa e ensino em saúde em qualquer nível de complexidade.

\section{Classificação dos riscos biológicos}

\begin{tabular}{|c|c|c|}
\hline $\begin{array}{c}\text { RISCOS } \\
\text { BIOLÓGICOS }\end{array}$ & $\begin{array}{c}\text { FONTE } \\
\text { GERADORA }\end{array}$ & RECOMENDAÇÖES \\
\hline $\begin{array}{l}\text { Contato com } \\
\text { fluido corporal }\end{array}$ & $\begin{array}{l}\text { Espino de secre- } \\
\text { cöes durante os } \\
\text { procedimentos, } \\
\text { reaproveitarcento } \\
\text { de frascos, esva- } \\
\text { ziar porto-vac, } \\
\text { aspirar pacientes }\end{array}$ & $\begin{array}{l}\text { Aumentar a atençäo e o } \\
\text { treinamento } \\
\text { Usar óculos e máscaras } \\
\text { Utilizar materiais mais } \\
\text { Seguros } \\
\text { Fazer exames periódicos }\end{array}$ \\
\hline $\begin{array}{l}\text { Limpezae higiene } \\
\text { dos saritánios }\end{array}$ & Odor, sujidade & $\begin{array}{l}\text { Aumentar a frequència da } \\
\text { limpeza }\end{array}$ \\
\hline
\end{tabular}

Fonte: Benatti e Nishide, 2000. 


\section{Riscos infecciosos}

Profissionais da área de saúde e outros trabalhadores que exercem suas atividades em laboratórios, estão sob risco de desenvolver doença profissional por exposição a agentes infecciosos, radiação, produtos químicos tóxicos e inflamáveis, entre outros. A seguir será descrito os tipos de infecções que os profissionais estão expostos:

- Infecção aérea - infecção microbiana adquirida através do ar e dos agentes infectantes nele contidos.

- Infecção critogénica - infecção de porta de entrada desconhecida.

- Infecção direta - infecção adquirida por contacto com um indivíduo doente.

- Infecção endógena - infecção devido a um microorganismo já existente no organismo, e que, por qualquer razão, se torna patogénico.

- Infecção exógena - infecção provocada por microorganismos provenientes do exterior.

- Infecção focal - infecção limitada a uma determinada região do organismo.

- Infecção indireta - infecção adquirida através da água, dos alimentos ou por outro agente infectante, e não de indivíduo para indivíduo.

- Infecção nosocomial - infecção adquirida em meio hospitalar.

- Infecção oportunista ou Oportunística - infecção que surge por diminuição das defesas orgânicas.

- Infecção puerperal - infecção surgida na mulher debilitada e com defesas diminuídas, logo após o parto.

- Infecção secundária - infecção consecutiva a outra e provocada por um microorganismo da mesma espécie.

- Infecção séptica ou Septicemia - infecção muito grave em que se verifica uma disseminação generalizada por todo o organismo dos agentes microorgânicos infecciosos.

- Infecção terminal - infecção muito grave que, em regra, é causa de morte.

É de extrema importância a elaboração de rotinas gerais e específicas para os procedimentos de limpeza e desinfecção de artigos e áreas.

\section{Riscos químicos}

Riscos químicos são causados por agentes químicos: substâncias químicas em forma sólida (poeiras), líquida (soluções) e gasosa (gases propriamente ditos e vapores de substâncias normalmente líquidas ou sólidas).

\section{Classificação dos riscos químicos}

\begin{tabular}{|c|c|c|}
\hline $\begin{array}{c}\text { RIscos } \\
\text { Químcos }\end{array}$ & $\begin{array}{c}\text { FONTE } \\
\text { GERADORA }\end{array}$ & RECOMENDACŌES \\
\hline $\begin{array}{l}\text { Inalação de } \\
\text { produt os } \\
\text { químicos }\end{array}$ & $\begin{array}{l}\text { Preparo de medi- } \\
\text { caçöes }\end{array}$ & $\begin{array}{l}\text { Utilizar máscaras } \\
\text { NËo veutilizar frascos }\end{array}$ \\
\hline
\end{tabular}

Fonte: Benatti e Nishide, 2000.

\section{Riscos ergonômicos}

Riscos ergonômicos são aqueles que se referem aos fatores necessários ao ajustamento ideal entre o homem e seu trabalho, e são de quatro tipos: biomecânicos: levantamento de peso, posturas inadequadas, movimentos repetitivos; ambientais: temperatura, umidade, ruído, contaminantes, geralmente associados a questões de conforto; sensoriais: cores e sinais auditivos; psicológicos: estresse, ritmo de trabalho, relacionamento.

Consta sobre a ergonomia no Manual de Legislação Atlas (2007):

- Esta Norma Regulamentadora visa a estabelecer parâmetros que permitam a adaptação das condições de trabalho às características psicofisiológicas dos trabalhadores, de modo a proporcionar um máximo de conforto, segurança e desempenho eficiente.

- As condições de trabalho incluem aspectos relacionados ao levantamento, transporte e descarga de materiais, ao mobiliário, aos equipamentos e às condições ambientais do posto de trabalho, e à própria organização do trabalho. 
- Para avaliar a adaptação das condições de trabalho às características psicofisiológicas dos trabalhadores, cabe ao empregador realizar a análise ergonômica do trabalho, devendo a mesma abordar, no mínimo, as condições de trabalho, conforme estabelecido nesta Norma Regulamentadora.

- Levantamento, transporte e descarga individual de materiais.

- Mobiliário dos postos de trabalho.

- Condições ambientais de trabalho

A organização do trabalho, para efeito desta NR, deve levar em consideração, no mínimo:

a) as normas de produção;

b) o modo operatório;

c) a exigência de tempo;

d) a determinação do conteúdo de tempo; e) o ritmo de trabalho;

f) o conteúdo das tarefas.

Classificação dos riscos ergonômicos

\begin{tabular}{|c|c|c|}
\hline $\begin{array}{c}\text { RISCOS } \\
\text { ERGONÔMICOS }\end{array}$ & $\begin{array}{c}\text { FONTE } \\
\text { GERADORA }\end{array}$ & RECOMENDAÇÖES \\
\hline $\begin{array}{l}\text { Esforço fisico/postura } \\
\text { não ergonômica }\end{array}$ & $\begin{array}{l}\text { Peso dos } \\
\text { pacientes } \\
\text { Manivela das } \\
\text { camas } \\
\text { Colocaçäo de } \\
\text { placa Raios-X } \\
\text { Transportes } \\
\text { monitores }\end{array}$ & $\begin{array}{l}\text { Usar equipamentos que } \\
\text { auxiliem o trabalhador } \\
\text { Substit uir por camas } \\
\text { hidráulicas } \\
\text { Colocar camas com } \\
\text { suporte de placa Raios-X } \\
\text { Monitores fixos por leito }\end{array}$ \\
\hline $\begin{array}{l}\text { Atitude automática e } \\
\text { nitmo excessivo }\end{array}$ & $\begin{array}{l}\text { Excesso de } \\
\text { procedimentos }\end{array}$ & $\begin{array}{l}\text { Proporcionar número de } \\
\text { trabalhadores de acordo } \\
\text { com procedimentos }\end{array}$ \\
\hline
\end{tabular}

Fonte: Benatti e Nishide, 2000.

\section{Condições físicas impróprias e dupla jornada de trabalho}

As condições de trabalho nos hospitais implicam em longas jornadas, no trabalho em turnos desgastantes (vespertino e noturno, domingos e feriados), nos rodízios, em multiplicidade de funções, repetitividade e monotonia, intensividade e ritmo excessivo de trabalho, ansiedade, esforços físicos, posições incômodas, na separação do trabalho intelectual e manual, no controle das chefias, desencadeando acidentes e doenças (Alves,1995).

Muitas vezes, trabalhadores com problemas de saúde, quer físicos e/ou mentais, segundo Moura (1992) transferem seus problemas para o trabalho, os quais podem ocasionar atrasos, faltas, descuido com o material e queda na qualidade do trabalho executado.

Os riscos ocupacionais variam de acordo com as atividades exercidas e o meio ambiente. A sobrecarga de risco pode desencadear prejuízo para a saúde do trabalhador, provocando o absenteísmo.

Considerando que, as faltas ao trabalho acarretam problemas na organização do trabalho, prejudicam a assistência de enfermagem prestada aos pacientes e indicam a existência de problemas preocupantes quando relacionados às condições de saúde, os autores sentiram se motivados a realizar o estudo ora apresentado.

\section{Administrador $\mathrm{X}$ hospital}

Observa-se nas últimas décadas, em vários países, uma mobilização em torno da aplicação de programas de qualidade nas organizações hospitalares, com o objetivo de incrementar seu gerenciamento e melhorar a eficiência destes serviços (Camacho, 1998). Dentro deste contexto, desenvolve-se no Brasil, já há alguns anos, instrumentos oficiais de avaliação do desempenho das organizações hospitalares do Sistema Único de Saúde, utilizando-se um conjunto de critérios que os hospitais devem preencher, a partir de padrões preestabelecidos, tendo por base a aplicação de conceitos e técnicas da qualidade total Quinto Neto e Gastal 
(1997). Fenômeno semelhante pode ser observado nos hospitais da rede privada suplementar, que fazem uso de certificações proferidas por organizações avaliadoras de reconhecimento internacional como diferencial de mercado, demonstrando uma crescente preocupação com a qualidade.

O hospital com as características observadas nos dias atuais é algo muito recente. Uma organização como instrumento de intervenção terapêutica com o objetivo de alcançar a cura de doentes é uma invenção relativamente nova. Segundo Foucault (1981), os primeiros hospitais datam do final do século 18.

É nesse período que a Academia de Ciências da França busca uma padronização para os hospitais existentes, a partir de uma série de viagens de pesquisa, cujo objetivo era estudar aspectos físicos e funcionais para transformar os depósitos de doentes da época em instituições que buscassem a assistência à saúde, um local de prática médica. Antes do século 18, os hospitais serviam para separar os enfermos da sociedade, para esperar a morte, não havendo quase nenhuma intervenção sobre a doença ou o doente.

De acordo com Mintzberg (1995), a organização hospitalar caracteriza-se por ser uma burocracia profissional do ponto de vista estrutural, onde o setor operacional tem importância, traciona e concentra o poder na organização. O seu mecanismo de controle dá-se por padronização de habilidades realizadas por órgãos fiscalizadores externos das diversas categorias profissionais. Isto lhe confere autonomia e independência da gerência estratégica, pois suas habilidades profissionais são definidas fora da organização em cursos profissionalizantes, ou seja, o estado da arte é um atributo das próprias corporações que desenvolvem seu trabalho no hospital. Tal condição enfraquece a vinculação com a organização e confere dificuldades adicionais como alta resistência às mudanças.

As organizações hospitalares, públicas ou privadas, estão inseridas num ambiente complexo e singular que as condiciona a um funcionamento inadequado diante da lógica da acumulação lucrativa dos mercados. Pois, independentemente de sua natureza, ambas as condições estão subordinadas a princípios éticos e legais que normatizam o setor saúde e às políticas governamentais, que colocam os hospitais frente a uma diversidade de interesses divergentes a contemplar.

Segundo Nogueira (1994), evidenciam-se os interesses dos usuários, que demandam assistência das mais variadas formas; os interesses dos trabalhadores da saúde, que buscam seu sustento e boas condições de trabalho; os interesses dos acionistas em se tratando de hospital privado, que objetiva o lucro; os interesses da rede de fabricantes e distribuidores de insumos, das empresas seguradoras e planos de saúde, que estabelecem uma relação comercial com o hospital; e, finalmente, os interesses dos poderes formalmente constituídos na gerência hospitalar e no governo, que têm nos objetivos técnicos e no alcance de metas programáticas da política de saúde o seu foco.

Além disso, a formação médica ainda é fundamentada no modelo flexneriano, que dá ênfase à clínica em sua dimensão biológica e no qual os aspectos sociológicos, políticos e administrativos ficam relegados ao segundo plano. Estas questões são pouco observadas nos currículos das escolas médicas, por isso há obstáculos à adesão dos médicos aos programas de qualidade, por deficiência e limitação na sua formação (OMS,1994).

\section{O enfermeiro administrador na atuação diante dos riscos hospitalares}

Em nível de discurso, os administradores hospitalares colocam que, nas suas práticas gerenciais, tudo é negociado e envolve a participação de seus subordinados. Já com relação aos seus superiores, a maioria afirma que a negociação e a participação são mais restritas. O papel de facilitador, catalisador e líder ainda está perdendo para o de centralizador e chefe, como colocado por Fayol.

O papel do administrador de alto nível envolve as seguintes capacidades: estratégica, racionalidade administrativa e habilidades interpessoais de liderança e de tomada de decisão, como colocado por Motta (1990) (op. cit. referencial teórico) que, de certa forma, não vêm sendo plenamente assimiladas pelos gestores entrevistados, de acordo com suas respostas.

Segundo Motta (1990), faz alusão ao regente de uma orquestra para definir administrador: "Ser administrador é como reger uma orquestra, onde as partituras mudam a cada instante, os músicos têm a liberdade para marcar seu próprio compasso. " $\mathrm{O}$ autor cita ainda algumas características necessárias para que os gestores se adaptem às mudanças atualmente com maior eficiência. Ele salienta que uma função gerencial de alto nível envolve a capacidade de:

- conhecer, desenvolver alternativas e responder às demandas, necessidades e apoios comunitários público e clientela (estratégia);

- $\quad$ agir segundo etapas de uma ação racional calculada (racionalidade administrativa);

- reativar e reconstruir constantemente a ideia de missão e dos objetivos comuns, conduzindo as pessoas à ação cooperativa desejada (liderança e habilidades interpessoais); 
- tomar decisões, interagir com grupos e indivíduos, resolver problemas e conflitos à medida que surgem (processo decisório organizacional).

Motta (1990), coloca a importância do conhecimento por parte do dirigente, das dimensões formais e previsíveis do processo decisório organizacional, enfocando:

- as formas de divisão e especialização do trabalho, bem como a distribuição do poder e da autoridade para melhor utilizar os recursos disponíveis;

- a maneira de captar, processar e analisar informações externas e internas para melhor agir na formulação de políticas, estratégias organizacionais e na solução de problemas;

- as alternativas de definição de processos sequenciais interdependentes que levam ao alcance de resultados, para poder atuar na coordenação e no controle;

- as formas comportamentais humanas - individuais e grupais - que se estabelecem em uma organização de trabalho, para saber que ações gerenciais produzem respostas comportamentais mais adequadas.

São as principais habilidades e conhecimentos necessários ao administrador hospitalar, segundo a percepção dos entrevistados, são:

- $\quad$ atuação como facilitador;

- relações humanas;

- habilidade para gerenciar conflitos;

- postura participativa;

- atuação como catalisador;

- $\quad$ capacidade para criar um ambiente favorável;

- negociação;

- liderança;

- flexibilidade;

- conhecimento das áreas funcionais;

- conhecimento das técnicas e visão integrada da administração;

- conhecimento de finanças;

- conhecimento dos mecanismos da área hospitalar e suas relações culturais e éticas.

Hoje o trabalho constitui uma das práticas mais importantes da vida do ser humano, porque é dessa atividade que o homem tira os elementos para sua própria subsistência familiar. Entretanto, o homem não deve trabalhar apenas pelo salário que recebe, mas também pela satisfação pessoal que deve sentir na sua realização e pelos resultados que colhe através do seu próprio esforço. Quanto à Saúde do Trabalhador, ela é compreendida como um conjunto de práticas teóricas interdisciplinares - técnicas, sociais, humanas - e interinstitucionais realizadas por diferentes atores situados em espaços sociais distintos e informados por uma mesma perspectiva comum.

A passagem da produção para o mercado do trabalho assalariado representa a passagem da independência à dependência. A passagem da elaboração completa do produto - base do orgulho profissional, à contribuição parcial e fragmentária, pode trazer tão somente a sensação de insignificância. A passagem, enfim, do domínio do processo de trabalho em sua totalidade à inserção no seio de uma organização estruturada em torno de um poder hierárquico, alheia o trabalhador, (Enguita, 1989).

O processo de trabalho da saúde aplica modelos de sistematização de assistência que não encerra somente no primeiro, incluem-se aqueles que traduzem ruptura abrupta do equilíbrio entre as condições e o ambiente de trabalho e a saúde do trabalhador, como os acidentes do trabalho e as intoxicações agudas de origem profissional. O segundo grupo inclui agravos de caráter crônico: a doença profissional típica, definida como aquela inerente ou peculiar a determinado ramo de atividade, (Mendes \& Dias, 1991).

$\mathrm{O}$ acidente de trabalho caracteriza-se por uma interação direta, repentina e involuntária entre a pessoa e o agente agressor em curto espaço de tempo. Esse tipo de acidente está relacionado aos riscos ocupacionais, ou seja, aos elementos presentes no ambiente de trabalho que podem causar danos ao corpo do trabalhador, ocasionando doenças ocupacionais adquiridas em longo prazo. No caso dos trabalhadores hospitalares, entre os riscos a que estão expostos sobressaem: os agentes físicos ambientais (calor, frio, ruído e radiações); os agentes químicos (detergentes, desinfetantes, medicamentos como os antibióticos de última geração); os agentes biológicos (vírus, bactérias) e as doenças do trabalho (problemas de coluna, estresse, fadiga, hipertensão, etc). Tais riscos ocupacionais podem afetar a visão desses profissionais. Os trabalhadores de saúde constituem a maior representatividade de pessoal dentro do hospital e sua primordial atividade 
caracteriza-se na promoção da saúde a um número elevado de pessoas. No desempenho dessas atividades, entretanto, impõem se rotinas, elevada carga horária semanal e procedimentos executados com reduzido quadro de profissionais para cumprir essas funções, (Miranda, 1998).

Buscamos demonstrar para o ambiente hospitalar, algumas funções com os riscos inerentes ao desenvolvimento destas atividades (Mendes \& Dias, 1991; Bulhões, 1994; Alves, 1988; Alexandre, 1993; Lopes, 1998):

- serviço de enfermagem: contato com substâncias, compostos ou produtos químicos em geral, risco biológico permanente, esforço físico, levantamento e transporte manual de peso, postura inadequada, trabalho noturno, situações causadoras de estresse psíquico, na maioria das vezes arranjo físico inadequado, materiais inadequados ou defeituosos, iluminação inadequada;

- auxiliares de limpeza: contato com substâncias, compostos ou produtos químicos em geral, risco biológico permanente, esforço físico, levantamento e transporte manual de peso, postura inadequada, trabalho noturno, situações causadoras de estresse psíquico, na maioria das vezes arranjo físico inadequado, materiais inadequados ou defeituosos, iluminação inadequada, contato com lixo

- auxiliares de lavanderia: contato com substâncias, compostos ou produtos químicos em geral, risco biológico permanente, esforço físico, levantamento e transporte manual de peso, postura inadequada, trabalho noturno, situações causadoras de estresse psíquico, na maioria das vezes arranjo físico inadequado, materiais inadequados ou defeituosos, iluminação inadequada;

- pessoal de cozinha e copa: exposição ao calor, trabalho noturno, máquinas e equipamentos sem proteção, arranjo físico inadequado, materiais inadequados ou defeituosos, probabilidade de incêndio ou explosão;

- auxiliares de costura: postura inadequada, monotonia e repetitividade, iluminação inadequada;

- auxiliar de farmácia e almoxarifado: levantamento de peso, postura inadequada, arranjo físico inadequado;

- serviços de escritório (recepcionista, secretária, auxiliar de escritório, digitador, office-boy, escriturário, etc.): iluminação deficiente, postura inadequada, lesões por esforços repetitivos - DORTs, monotonia e repetitividade;

- técnicos de RX: exposição a radiação. O objetivo do Hospital é descrever riscos destas atividades hospitalares é fundamentar os dados da pesquisa, que envolve os trabalhadores de maneira geral de um hospital de médio porte, sem especificar ou salientar nenhuma das atividades em detrimento de outras, visto que buscamos compreender qual a responsabilidade dos profissionais de saúde hospitalar, quanto a sua própria saúde.

Hoje o trabalho constitui uma das práticas mais importantes da vida do ser humano, porque é dessa atividade que o homem tira os elementos para sua própria subsistência familiar. Entretanto, o homem não deve trabalhar apenas pelo salário que recebe, mas também pela satisfação pessoal que deve sentir na sua realização e pelos resultados que colhe através do seu próprio esforço. Quanto à Saúde do Trabalhador, ela é compreendida como um conjunto de práticas teóricas interdisciplinares - técnicas, sociais, humanas - e interinstitucionais realizadas por diferentes atores situados em espaços sociais distintos e informados por uma mesma perspectiva comum.

A passagem da produção para o mercado do trabalho assalariado representa a passagem da independência à dependência. A passagem da elaboração completa do produto - base do orgulho profissional, à contribuição parcial e fragmentária, pode trazer tão somente a sensação de insignificância. A passagem, enfim, do domínio do processo de trabalho em sua totalidade à inserção no seio de uma organização estruturada em torno de um poder hierárquico, alheia o trabalhador, (Enguita, 1989).

O processo de trabalho da saúde aplica modelos de sistematização de assistência que não encerra somente no primeiro, incluem-se aqueles que traduzem ruptura abrupta do equilíbrio entre as condições e o ambiente de trabalho e a saúde do trabalhador, como os acidentes do trabalho e as intoxicações agudas de origem profissional. O segundo grupo inclui agravos de caráter crônico: a doença profissional típica, definida como aquela inerente ou peculiar a determinado ramo de atividade, (Mendes \& Dias, 1991).

$\mathrm{O}$ acidente de trabalho caracteriza-se por uma interação direta, repentina e involuntária entre a pessoa e o agente agressor em curto espaço de tempo. Esse tipo de acidente está relacionado aos riscos ocupacionais, ou seja, aos elementos presentes no ambiente de trabalho que podem causar danos ao corpo do trabalhador, ocasionando doenças ocupacionais adquiridas em longo prazo. No caso dos trabalhadores hospitalares, entre os riscos a que estão expostos sobressaem: os agentes físicos ambientais (calor, frio, ruído e radiações); os agentes químicos (detergentes, desinfetantes, medicamentos como os antibióticos de última geração); os 
agentes biológicos (vírus, bactérias) e as doenças do trabalho (problemas de coluna, estresse, fadiga, hipertensão, etc). Tais riscos ocupacionais podem afetar a visão desses profissionais. Os profissionais de saúde constituem a maior representatividade de pessoal dentro do hospital e sua primordial atividade caracterizase na promoção da saúde a um número elevado de pessoas. No desempenho dessas atividades, entretanto, impõem se rotinas, elevada carga horária semanal e procedimentos executados com reduzido quadro de profissionais para cumprir essas funções, (Miranda, 1998).

\section{Considerações finais}

Este estudo possibilitou identificar e avaliar o administrador de enfermagem diante dos riscos ocupacionais a que estão expostos, bem como a importância desses administradores dentro das unidades hospitalares.

O acidente do trabalho hospitalar está se tornando cada vez mais uma preocupação para os administradores hospitalares, pois além de gerar prejuízos para a saúde dos trabalhadores envolvidos onera o hospital de diversas maneiras principalmente pelo afastamento do trabalhador de seu posto de trabalho.

No entanto, torna-se importante utilizar instrumentos de medida de gravidade, avaliar as necessidades dos cuidados e a demanda de trabalho de enfermagem, buscando profissionais qualificados que dediquem maior tempo na atenção às necessidades de apoio emocional e informação aos pacientes e familiares, otimização de recursos, redução de custos e, consequentemente, qualidade e humanização da assistência.

Os trabalhadores hospitalares devem mesmo, sentir e se contextualizar enquanto trabalhador, e ver que as medidas de segurança não existem apenas para o paciente, mas para ele também, e que ele tem direito a isto. Deve conhecê-las e reivindicá-las, rompendo com o silêncio e a alienação nos ambientes de trabalho, seja do trabalho hospitalar e de outras unidades de serviços de saúde.

O investimento em recursos humanos e materiais usam de EPI, atualização de esquemas vacinais, ênfase nas precauções de contato, gotículas e aerossóis de forma a evitar transmissão de doenças, medidas de redução do estresse ocupacional e da violência no ambiente de trabalho, bem como valorização da profissão e adequação de jornadas de trabalho também são fundamentais na melhoria das condições de trabalho e até mesmo no âmbito de administração hospitalar, haja vista a redução de despesas.

Acredita-se que deveria existir em cada unidade hospitalar uma concentração de esforços e recursos para reconhecimento dos riscos no ambiente de trabalho, treinamento e conscientização de práticas seguras e fornecimento de forma contínua e uniforme dos dispositivos de segurança aos trabalhadores da área da saúde.

\section{Referências}

Albaladejo, R., Villanueva, R., Ortega, P., Astasio, P., Calle, M. E., \& Domínguez, V. 2004. Síndrome de Burnout en el personal de enfermería de un hospital de Madrid. Revista Española de Salud Pública, 78, 505-516.

Alexandre, N. M. C. 1993. Contribuição ao estudo das cérvico dorso lombalgias em profissionais de enfermagem. Dissertação de mestrado (Escola de Enfermagem). Ribeirão Preto, SP: USP.

Alves, A. R. A. 1995. Avaliação diagnostica dos índices de absenteísmo da equipe de Enfermagem de um Hospital de Ensino. Revista Latino-Americana de Enfermagem, 8(5), 44-51.

Alves, D.B. 1988. Condições de trabalho na enfermagem: aspectos teóricos. In Anais do congresso brasileiro de enfermagem. Salvador, BA.

Aquino, E. M. L. D., Araujo, M. J. S., Menezes, G. M. D. S., \& Marinho, L. D. F. B. 1993. Saúde e trabalho de mulheres profissionais de enfermagem em um hospital público de Salvador, Bahia. Revista Brasileira de Enfermagem, 46(3-4), 245-257.

Azevedo, C. S. 1993. Gerência hospitalar: a visão dos diretores de hospitais públicos do município do Rio de Janeiro. Dissertação de mestrado (Instituto de Medicina Social). Rio de Janeiro, RJ: Universidade Federal do Rio Janeiro.

Benatti, M. C. C., \& Nishide, V. M. 2000. Elaboração e implantação do mapa de riscos ambientais para prevenção de acidentes do trabalho em uma unidade de terapia intensiva de um hospital universitário. Revista Latino-Americana de Enfermagem, 8(5), 13-20.

Benevides-Pereira, A. M. T. (2002). Burnout: o processo de adoecer pelo trabalho. Burnout: quando o trabalho ameaça o bem-estar do trabalhador, 4, 21-91. 
Bulhões, I. 1994. Riscos do trabalho de enfermagem (2a ed.). Rio de Janeiro, RJ: Folha Carioca.

Camacho, J. L. T. 1998. Qualidade total para os serviços de saúde. São Paulo, SP: Nobel.

Carlotto, M. S., \& Gobbi, M. D. 1999. Síndrome de Burnout: Um problema do indivíduo ou do contexto de trabalho? Alethéia, 10, 103-114.

Conselho Federal de Enfermagem [COFEN]. 1985. A enfermagem nas instituições de saúde no Brasil. Rio de Janeiro, RJ: COFEN.

Enguita, M. F. 1989. A face oculta da escola: educação e trabalho no capitalismo. Porto Alegre, RS: Artes Médicas.

Esposito, I. 1980. Repercussões da fadiga psíquica no trabalhador e na empresa. Revista Brasileira de Saúde Ocupacional, 8(32), 37-45.

Foucault, M. 1981. O nascimento do hospital. In Microfísica do poder. Graal, Rio de Janeiro, RJ: Graal.

França, A. C. L., \& Rodrigues, A. L. 1997. Estresse e trabalho: Guia básico com abordagem psicossomática. São Paulo, SP: Atlas.

Funden. 1996. El riesgo profissional. In Manual de Salud Laboral. Madrid, ES: Serie enfermería.

Kirchhof, A. L. C., \& Capellari, C. (2004). Descrição das comunicações de acidentes de trabalho registradas no Instituto Nacional de Seguridade Social de Santa Maria, RS, no ano de 2000. Revista Gaúcha de Enfermagem, 25(2), 194.

Lakatos, E. M., \& Marconi, A. 2002. Técnicas de pesquisa (5a ed.). São Paulo, SP: Atlas.

Lautert, L. (1997). O desgaste profissional: uma revisão da literatura e implicações para a enfermeira. Revista gaúcha de enfermagem, 18(2), 83.

Lima, E. D. R. P., \& Carvalho, D. V. 2000. Estresse ocupacional. Revista Nursing, 3(22), 30-34.

Lipp, M. E. N. 1996. Stress: conceitos básicos. In: M.E.N. Lipp (Org.). Pesquisas sobre stress no Brasil: sáude, ocupações e grupos de risco. Campinas, SP: Papirus.

Lopes, M. J. M. 1988. O trabalho da enfermeira: nem público, nem privado, feminino, doméstico e desvalorizado. Revista Brasileira de Enfermagem, 41(3/4).

Manuais de Legislação Atlas. 2007. Segurança e Medicina do Trabalho (6a ed.). Monte Alto, SP: Editora Atlas.

Marziale, M. H. P. 1995. Condições ergonômicas da situação de trabalho, do pessoal de enfermagem, em uma unidade de internação hospitalar. Tese de doutorado (Escola de Enfermagem de Ribeirão Preto). Ribeirão Preto, SP: Universidade de São Paulo.

Marziale, M. H. P., Melo, M. R. A., \& Silva, E. M. (1991). A postura corporal adotada pela enfermeira durante a execuçäo de seu trabalho. Revista Brasileira de Saúde Ocupacional, 19-24.

Maslach, C., \& JacksoN, S. E. (1985). Maslach Burnout Inventory (2a ed.). Palo Alto, CA: Consulting Psychologist Press.

Melo, C. 1986. Divisão social do trabalho e enfermagem. São Paulo, SP: Cortez.

Mendes, R., \& Dias, E. C. 1991. Da medicina do trabalho à saúde do trabalhador. Revista de Saúde Pública, 25(5), 341-349.

Ministério do Trabalho. 2001. Normas regulamentadoras: segurança e medicina do trabalho (48a ed.) São Paulo, SP: Atlas.

Mintzberg, H. A. 1995. Adhocracia. In Criando organizações eficazes: estruturas em cinco configurações. São Paulo, SP: Atlas.

Miranda C. R. 1998. Introdução à saúde no trabalho. São Paulo, SP: Atheneu.

Miranda, E. J. P., \& Stancato, K. 2008. Riscos à Saúde da Equipe de Enfermagem em Unidade de Terapia Intensiva: Proposta de Abordagem Integral da Saúde. Revista Brasileira de Terapia Intensiva, 20(1), 68-76.

Motta, P. R. 1990. Administração Contemporânea. A Ciência e a Arte de Ser Dirigente. Rio de Janeiro, RJ: Record.

Moura, G. M. S. S. D. (1992). O estudo da satisfaçäo no trabalho e do clima organizacional como fatores contributivos para o ser saudável no trabalho da enfermagem. Texto \& Contexto Enfermagem, 167-79.

National Institute for Occupational Safety and Health [NIOSH]. 1988. Guidelines for protecting the safety and health care workers [online]. Atlanta, GA. Disponível em: <http:// www.cdc.gov/niosh/hcwold1.html>

Newmed. 2007. Mapa de riscos. Curitiba. Disponível em: www.newmedt.com.br/UserFiles/12.JPG.

Nogueira, R. P. 1994. Perspectivas da qualidade em saúde. Rio de Janeiro. RJ: Qualitymark. 
Oliveira, S. L. 2001. Metodologia da pesquisa. In Tratado de Metodologia Cientifica (2a ed.). São Paulo, SP: Pioneira Thonson Learning.

Organização Mundial da Saúde [OMS]. 1994. Contribuições sobre a gestão da qualidade em educação médica. Série Desenvolvimento de recursos humanos. Brasília, DF: OMS.

Pottler, R. M., \& Estryn-Behar, M. 1979. L’Ergonomie en milieu hospitalier. Actes Dir XV Congres de Ia societé D’Ergonomie de Langue Française. Paris, FR.

Quinto Neto, A., \& Gastal, F. L. 1997. Acreditação hospitalar: proteção dos usuários dos profissionais e das instituições de saúde. Porto Alegre, RS: Ed. Dacasa.

Ruiz, J. A. 1996. Metodologia cientifica: guia para eficiência nos estudos (4a ed.). São Paulo, SP: Atlas.

Severino, A. J. 1996. Metodologia do trabalho científico (20a ed.). São Paulo, SP: Rev ampl.

Spilberger, C. 1979. Understanding stress and anxiety. New York, NY: Haper e Row Publishers.

Takeda, E. 1996. Tuberculose: um estudo de sua situação entre pacientes internados e equipe de enfermagem de um hospital escola de Ribeirão Preto, São Paulo. Dissertação de mestrado. Ribeirão Preto, SP: Escola de Enfermagem de Ribeirão Preto/USP.

Wisner, A. 1987. Por dentro do trabalho: ergonomia, método \& técnica. São Paulo, SP: FTD/Oboré.

\section{Minicurrículo}

José Angelo Leal Braga. Mestre em Terapia Intensiva pela Sociedade Brasileira de Terapia Intensiva, PósGraduado em Terapia Intensiva pelo Instituto Brasileiro de Terapia Intensiva, Especialista em Enfermagem do Trabalho pelo Centro Universitário São Camilo, Especialista em Administração Hospitalar pela Secretaria Estadual de Saúde do Rio de Janeiro, Graduado em Enfermagem pelo Centro Universitário Serra dos Órgãos UNIFESO. Docente e Preceptor do Curso de Graduação em Enfermagem do Centro Universitário Serra dos Órgãos - UNIFESO. Membro da Sociedade Brasileira de Medicina Intensiva e Membro da ERWS (Emergency Rescue World Society).

Como citar: Braga, J.A.L. 2020. Administradores diante dos riscos ocupacionais que envolvem as atividades da equipe de enfermagem no ambiente hospitalar. Pubsaúde, 3 , a021. DOI: https://dx.doi.org/10.31533/pubsaude3.a021

Recebido: 29 jan. 2020.

Revisado e aceito: 18 mar. 2020.

Conflito de interesse: os autores declaram, em relação aos produtos e companhias descritos nesse artigo, não ter interesses associativos, comerciais, de propriedade ou financeiros que representem conflito de interesse.

Licenciamento: Este artigo é publicado na modalidade Acesso Aberto sob a licença Creative Commons Atribuição 4.0 (CC-BY 4.0). 